\title{
Understanding Informal Volunteer Behavior for Fast and Resilient Disaster Recovery: An Application of Entrepreneurial Effectuation Theory
}

\begin{tabular}{|r|l|}
\hline Journal: & Disaster Prevention and Management \\
\hline Manuscript ID & DPM-05-2019-0151.R3 \\
\hline Manuscript Type: & Research Paper \\
\hline Keyword: & $\begin{array}{l}\text { Disaster relief, Entrepreneurship, Informal Volunteer, Effectuation, Case } \\
\text { study, Opportunity Recognition, Disaster response and recovery, } \\
\text { Disaster }\end{array}$ \\
\hline Authors: & Javier Monllor, Ignacio Pavez, Stefania Pareti \\
\hline
\end{tabular}




\section{Introduction}

In most developed countries, emergency and disaster management relies largely on a workforce of professionals and volunteers affiliated with official agencies (Whittaker et al., 2015) but new technologies, increased connectivity, and social media now enable ordinary citizens to participate in emergency and disaster management (McLennan et al., 2015). Traditionally, their initiatives have been undervalued and viewed as a nuisance or liability (Helsloot and Ruitenberg, 2004; Scanlon, et al., 2014; Stallings and Quarantelli, 1985), however, the increasing disaster risks posed worldwide by anthropogenic climate change, populations shifts (Pachauri et al., 2014), population growth and urban development (Field et al., 2012) create a context in which the efforts of these informal volunteers will provide much of the additional surge capacity required to respond appropriately.

In this study, we examine informal volunteerism (the activities of people who work outside of formal emergency and disaster management arrangements) through the theoretical lens of Effectuation Theory to explain informal volunteer behavior and cognition and gain insight on how they develop their disaster relief efforts and how these can serve to increase community's capacity to absorb, recover, cope, 'bounce back', mitigate, withstand or resist the impacts of hazards (Aldunce et al., 2015). This is accomplished by speeding up disaster recovery, rebuilding the local economy and establishing long term solutions. The specific objectives of this research are twofold: first, to make a significant scholarly contribution by studying the informal volunteer phenomenon through the theoretical lens of Effectuation Theory; second, to provide theoretical and practical implications that can improve and assist recovery efforts so they can better serve rebuilding post-disaster societies and increase their resilience.

\section{Effectuation Theory}

Natural disasters are defined as the 'impact of an extreme natural event on an exposed, vulnerable society' (Mechler, 2003). Some authors (Cannon 1994; Weichselgartner, 2001) argue that the term "natural disaster" can be misleading as, for example, approximately $87 \%$ of the most recent natural disasters are climate-related extreme weather events (Monllor and Murphy, 2017), which has significant links with human causes. They posit that hazards are natural, but in general disasters are not, and should not be seen as the inevitable outcome of a hazard's impact (Cannon, 1994). The prevalence of climate-related extreme weather hazards calls for a shift away from managing for a relatively predictable future towards developing flexible and speedy responses to unpredictable, non-linear change (Farazmand, 2017). This context is one at which effectuation is 
especially suitable (Fisher, 2012; Morrish and Jones, 2019). Individuals who adopt an effectual approach work with the means within their control, use experimentation, select alternatives based on affordable loss, and maintain flexibility by adjusting when necessary. Instead of attempting to predict the future, they seek to control it by developing partnerships and securing precommitments from various stakeholders (Chandler et al., 2011; Dew et al., 2009).

Effectuation posits a theoretical framework of decision making in uncertain situations (Jiang and Rüling, 2019) that contrasts with the more traditional causation approach where processes take a particular effect as given and focus on selecting between means to create that effect (Sarasvathy, 2001). Effectuation emphasizes control rather than prediction and explains how new artifacts, such as products, firms, and markets, emerge rather than assuming them to be predetermined (Chandler et al., 2011; Sarasvathy, 2001; Sarasvathy et al., 2014). It posits that the means, resources, and capabilities one can mobilize constitute more influential determinants of action than the ends one might elect to pursue (Gregoire and Cherchem, 2017) with a planned strategy. Table 1 provides a contrast between causation and effectuation processes.

\section{Insert Table 1 Here}

Effectuation introduces four key principles (Deligianni et al., 2017; Palmié et al., 2018):

- Experimentation - Entails generating new opportunities from available means and involves a degree of trial-and-error learning (McGrath, 1995). Investments in trial-and-error experiments help identify potential new solutions to problems and outcomes result in "new, discomfiting information" (Sarasvathy et al., 2014) that permits individuals to abandon infertile experimental actions early (Chandler et al., 2007; 2011).

- Flexibility - Relates to acknowledging unexpected events and leveraging them into unexpected contingencies. Unforeseen events are perceived as opportunities rather than threats and are leveraged (Chandler et al., 2007, 2011; Dew et al., 2009). Flexibility is beneficial (Vera and Crossan, 2005) because it promotes improvisation instead of selecting a single, "best" plan from the outset (Deligianni et al., 2017).

- Pre-commitments - Involves the creation of avenues for stakeholder self-selection and reaching out to network means in an attempt to find partners that help and support the effort. Ideas are disclosed early to get partners to commit and collaborate (Chandler et al., 2011; Sarasvathy, 2008). Pre-commitments have a direct impact on the actions taken and the opportunities chosen (Sarasvathy et al., 2014). 
- Affordable Loss - Comprises efforts to minimize the risks associated with overspending (Sarasvathy et al., 2014) or "find(ing) ways to reach the market(s) with minimum expenditures of resources" and losses are deemed acceptable (Sarasvathy, 2001).

\section{Informal Volunteerism}

Informal volunteerism has been defined as "the activities of people who work outside of formal emergency and disaster management arrangements to help others who are at risk or are affected by emergencies and disasters" (Whittaker et al., 2015) and who, in most instances, do so before formal organizations (Einolf et al., 2016). Whittaker et al. (2015) has developed three broad informal volunteer categories: emerging, extended and digital. Emerging informal volunteers are those who collaborate to satisfy unmet needs, whether perceived or real, and features improvisation and innovation. Emerging volunteers can partake in prevention and preparedness activities; thus, it can occur prior to a disaster. When organizations and groups without prior emergency or disaster functions extend their activities in order to volunteer, they fall within the Extended category. Extended volunteers often have intimate understanding of local needs and can draw on existing networks and resources to meet them. Finally, Digital informal volunteers are made possible by the increasing accessibility to information and communication technologies. These technologies allow individuals all over the world to participate in emergency and disaster management through the production and dissemination of essential emergency-related information.

\section{Methodology}

We apply a case study approach as informal volunteerism is a novel topic of inquiry and the setting is rare and uncontrollable. Case studies are considered one of the most appropriate methods when: 1) trying to understand how a phenomenon arises and evolves, 2) there is little control over behavioral events, 3) the topic of study is contemporary by nature (Yin, 2013; Lee and Saunders, 2017) and 4) in the early phases of theory building (Gibbert et al., 2008),.

To assure analytic rigor, we used an embedded multiple case design, which consists of multiple cases and multiple units of analysis (Cresswell and Miller, 2000) that are embedded in the same or a similar context. The 'embedded multiple case' has two main advantages: First, it allows contrasting of cases to discern the extent to which predicted patterns of behavior are observed across cases (i.e. a multiple-case design). Second, it allows observation of similarities and differences among sub-units within the same case (embedded design) (Yin, 2014). These 
advantages are enhanced if the case uses multiple sources of evidence, establishes a chain of evidence, addresses rival explanations, and uses a replication logic to make comparisons among cases and units of analysis (Yin, 2014).

We studied the behavior of individual volunteers (units of analysis) in the context of three disasters to compare and contrast: (1) 2017 Hurricane Maria in Puerto Rico, (2) 2014 Valparaiso Fire in Chile and (3) the 2010 Chile Earthquake (See Table 2).

Insert Table 2 Here

To build each case we developed a protocol, which included the research objectives, the theoretical framework, data collection, data analysis, and a template for case study report. We designed the case protocol so that we could establish a chain of evidence (i.e. sorting the participant's experience in chronological order), address rival explanations (i.e. using theoretical sampling to find cases with different attributes), and compare and contrast cases using a replication logic (i.e. creating a set of shared categories for case study elaboration and report) (Yin, 2014). First step was to undertake a thorough online and personal network search to identify potential individuals that demonstrated evidence of informal volunteerism. We then proceeded to analyze the data, create initial profiles of each case and parse those individuals who fit the definition of an informal volunteer (See Table 2). This selection process was guided by the assumption of a research gap concerning the development of goals and actions by informal volunteers after a disaster (Strandh \& Eklund, 2018). The next step consisted of contacting these volunteers and asking them to participate in the study. To add variance and rival explanations, we also included cases of individuals that volunteered for established relief organizations. Hence, the interviewees were selected strategically (Patton, 2015) with the purpose of discussing and contrasting different types of disasters and varying volunteer types (Strandh, 2019; Whittaker et al., 2015). An interview format was considered appropriate as our aim was to capture the volunteers' experience and perceptions. It allowed us to focus on a topic of inquiry and gain knowledge about what they perceive to be important (Yin, 2013).

Finally, we conducted eight semi-structured interviews with the goal of eliciting discussion around participants' experience. Examples of questions included: Did you have a previous vision with respect to what you wanted to accomplish? (relates to the Experimentation Principle), Did you have to change your plan at any time during your relief effort? (Relates to the Flexibility Principle), 
What resources did you require during your relief effort? Where they personal resources or come from a third party? (relates to the Pre-Commitments and Affordable Loss Principles). All interviews were conducted by phone, lasted between 45 and 60 minutes, and were recorded and transcribed by the authors, which proceeded to divide the data into smaller units of one or a few sentences.

Based on the four effectuation principles (flexibility, experimentation, pre-commitments and affordable loss) we created a codebook and two authors independently scoured the transcribed units to take note of whether any of the principles were present. The categorization of the data resulted in $91.5 \%$ agreement between both authors, who then discussed the differences until a consensus was reached. All the information was put in chronological order to make sense of the emerging process of informal volunteerism, so as to understand if, how and why effectuation principles were deployed over time. We used the constant comparative method (Corbin and Strauss, 2015; Glaser and Strauss, 2017) to assure that the categories and themes that emerged from data were consistent across cases and linked to established theoretical constructs.

\section{Findings}

\section{Hurricane Maria}

In 2017 Puerto Rico was hit by Hurricane Maria, a category 5 hurricane. It's considered the tenth most intense Atlantic hurricane on record, causing nearly $100 \%$ of the island to lose electricity (Hincks, 2017) and indirectly causing the death of more than two thousand citizens (Robles et al., 2017).

The three volunteers interviewed for this case (See Table 2) belong to the Emerging Volunteer category (Whittaker et al., 2015). All three subjects were located in the United States and relocated to Puerto Rico. Their first move was to look at the means at their disposal to guide their actions and the solutions they pursued, as per the Experimentation Principle. Ethan owner of a medical equipment company had access to a chartered plane. Based on this, he saw an opportunity to bring medical equipment, supplies and medicine to the island. Carlos had family on the island and used his own personal reserves to bring needed lanterns and batteries. Finally, Jesse had prior experience working in disaster zones and a network of war veterans, so he flew over to deliver food and water. 
Upon arrival, Jesse expected to encounter a lack of food but realized that local stores had stock but were unable to sell it due to a lack of electricity and communications in a country where most people rely on government funding that is made available through an electronic debit card. Consequently, Jesse abandoned his plan and decided to develop and install a solar powered satellite communications system that would allow these transactions to take place. This fluidity and responsiveness is an essential component of the Experimentation Principle. Volunteers grope along (Dimov, 2010) and generate new information that helps them iterate and discover new opportunities (Arend et al., 2015). As Jesse states "We piloted it, tested it, showed it worked and scaled the project ... in a couple of weeks." His experience is mirrored by Ethan who commented that "It was iterative. We had no idea what we were gonna do." By applying the Experimentation Principle, informal volunteers can "make assumptions which are difficult to test before proceeding to action" (Brinkmann et al., 2010).

In addition to available means, the volunteers also relied on the Pre-commitments Principle to guide their decisions and actions. They were willing to "work with any and all self-selected stakeholders" (Sarasvathy, 2008) and "coordinate some of their decisions with them" (Palmié et al., 2018). Ethan didn't settle on the positive impact of his donations; he also convinced his business and personal networks to commit over two thousand pounds of additional medicine and supplies. Carlos' friends created Happy Helpertons to help with fundraising and support his efforts. Through their own initiative they became stakeholders and directly impacted Carlo's initial idea.

The evolution of Jesse's and Carlos' relief efforts, from donating food and water to installing a satellite communication system and from donating lamps and batteries to supplying solar lamps and water filters are examples of the Flexibility Principle. Flexibility promotes the use of improvisation and enables creative and nonroutine responses to situations in which programmed actions are difficult (Vera and Crossan, 2005) and allows individuals to shape opportunities as information emerges (Wiltbank et al., 2010). Carlos' solutions were shaped by new information and unexpected contingencies. After arriving, he realized that his original idea was unsustainable due to transportation difficulties and with no trash pickup available, discarded batteries worsened an already ravaged natural environment. Consequently, he identified a solar lamp supplier and spent three weeks distributing them, only to pivot again to solve the potable water problem. He allied himself with an organization that produced water filters and commenced their distribution. 
A year later, his efforts pivoted again: "I have adapted to continue helping as the situation changes. Now it's education to prepare for future disasters."

Finally, and contrary to theory, volunteers tended to disregard the Affordable Loss Principle. Volunteers believed the needs were so great and the stakes so high that risks to personal financial resources were ignored. Affordable Loss would've entailed efforts to minimize and control risks associated with overspending (Sarasvathy et al., 2014) and potential losses (Brettel et al., 2012). When given a list of direly needed medical supplies Ethan's first thought was that "a spending limit is not an option." He also flew to Puerto Rico, with no experience working in disaster zones, going so far as to put his personal safety at stake. Jesse, lacking government support, purchased upwards of thirty thousand dollars of equipment with his credit card.

\section{Valparaiso Fire}

Our second case covers the 2014 "Mega-fire" that ravaged nearly one thousand hectares of the Valparaiso region in Chile. The fire claimed the lives of fifteen people, injured more than five hundred and displaced approximately twelve thousand (Reszka and Fuentes, 2015). To assist, Sofia utilized a friend's hostel (employing the Pre-commitments Principle), to set up a center of operations and receive, store and distribute supplies. Initial donations came from Sofia's network, but later started arriving by the thousands from all over the country. Pre-commitments were also sought to help build houses, clear out debris and recruit additional volunteers. These efforts impacted day to day actions and plans, influencing the enacted opportunities. Volunteers assessed the means available: "First step was to get people with resources, then (emphasis added) create a daily plan" and acted based on what challenges they encountered: "More than planning by us, it was on-the-go planning." - Sofia. Experimentation lead to trial and error experiments as not all actions would succeed. Sofia's states: "Every time we acted differently. It was a difficult job to accomplish as one tries to help, but not everything one does actually helps." Her original space transformed to a community center, a place to host activities and classes. Her duties also evolved and she became an intermediary between the community and the government, helping with paperwork and bureaucracy. Sofia also took great personal and financial risks visiting dangerous locations and exposing herself to potential landslides: "In the moment I didn't think about it, I just acted. The risk wasn't so much as to not act." Needs outweighed the risks and she even downplayed them, contrary the Affordable Loss Principle. 
Father Patricio's involvement (Alvarez, 2014; González, 2014) provides a alternative experience. After one family's home was consumed by the fire, the church opened its doors to them. This initiative grew into more than eighty families, turning the church's household into a makeshift shelter. The congregation thus falls under Whittaker's et al. (2015) Extended Volunteer category, expanding beyond their usual activities and their congregation members. A day after the fire, they had upwards of 340 volunteers, ready to clear debris and gather and distribute donations. Thus, they utilized their available means (the church's infrastructure and its members) to find opportunities and solutions. They applied the Flexibility Principle, expanding their activities from sheltering families to serving as a base camp and organization center. These decisions were made "without sizing up or much less calculating what this would entail." - Father Patricio. Decisions were made without concern for the risks involved and negative consequences were left to be dealt with later in disregard of the Affordable Loss Principle.

\section{Chile Earthquake}

The 2010 Chile earthquake is considered the sixth largest earthquake ever recorded in history, causing the death of five hundred (Muñoz, 2010), estimated damages of thirty billion dollars (\$US), the loss of fifteen thousand jobs (Special Earthquake Report: The Earthquake Engineering Research Institute, 2010) and the destruction of more than two hundred thousand houses (Concha-Saldias et al., 2015).

Camila's experience is of interest as she acted as an Emerging Informal Volunteer (Whittaker et al., 2015) and later joined Volunteer Psychologists of Chile, an Extended volunteer organization. As an Emerging volunteer she visited to the town of San Antonio to bring psychological support to children. Her education and experience as a psychologist and what she found at a local supermarket influenced her daily activities (Experimentation Principle, where available means guide actions and decisions.) True to the Affordable Loss Principle, Camila first determined what she could afford to lose, based on her available resources and if her initial plan didn't work out, the loss of the invested resources was something she could handle (Sarasvathy, 2001). She later learned of another community in worse condition, so she relocated, hoping to improve their situation (Flexibility Principle).

Her initial intervention contrast with those of her experience with Volunteer Psychologists of Chile. Their goal was to employ the capabilities and experience of psychologists to benefit those affected. Members had no prior disaster volunteer experience, placing them in the Extended 
Volunteer category. Camila was assigned to a specific geographical location, received professional training, participated in previously organized interventions, and took precautions based on evaluated risks. Camila states: "We went in groups so as not to take risks and be safer."; "We visited locations that were unsafe, but not dangerous." Although they followed a Causation approach, Effectuation principles were also applied. Daily activities were mostly funded by the volunteers, especially transportation, and there was no predetermined concept of success since their actions depended heavily on local conditions (Experimentation Principle). This suggests that Extended Volunteers combine Causation and Effectuation processes during their efforts. When applying a Causation process, the organization had previously envisioned goals, preselected locations and activities were directed at achieving their goals. However, as the situation was unpredictable and uncertain, Effectuation processes were also employed. Resources utilized were those of the volunteers themselves and actions determined upon arrival at the location (Affordable Loss and Flexibility Principles).

Loreto's volunteer experience with the University of Chile's Student Federation (classified under the Extended Volunteer category) mirrors that of Camila, where Causation Processes were mixed with Effectuation processes. The organization organized a trip to Batuco to provide volunteers with professional psychology training sessions on how to approach emergency situations. While these actions involved preplanning, application of the Flexibility Principle was essential for it was difficult for the organization to look ahead and plan their actions. As the following quote by Loreto demonstrates: "In the emergency, the vision was being forged in the moment, truthfully." Despite training, volunteers needed to be flexible and plan on the go, alert to unexpected contingencies. The Experimentation Principle was disregarded, since there was some preconception of where to go and what to do and while the resources utilized were determined on the spot, the strategy was guided by a predetermined mission, and the means at their disposal.

Lastly, Ignacio volunteered with Un Techo para Chile, an organization with many years of experience in disaster relief. Their goal was to help rebuild, erecting houses, bathrooms and classrooms and doesn't fit any category of informal volunteerism. Ignacio had no prior experience in construction and his tasks consisted of working in groups of 10 individuals that included construction experts to guide and supervise. All resources were selected and delivered by the organization, who also provided a detailed inventory of materials, manpower and building plans. We found no evidence of any of the Effectuation Principles as objectives were clearly defined, actions were planned and analyzed and all efforts and resources were directed toward achieving their predetermined goals. 


\section{Theoretical Implications}

In this study, we examined the behavior of informal volunteers and results have several implications for future theorizing and research. First, we posit that informal volunteers follow an effectual logic, an unfolding process of entrepreneurial action (Arend et al., 2015). Its principles enhance our understanding of their Goals and Actions (See Figure 1), and the variables that impact their development and constant evolution. Informal volunteers rely on their Available Means (networks, knowledge and resources) to take advantage of opportunities as they are recognized or created (Sarasvathy, 2001). This explains why Ethan's immediate plan, as owner of a medical equipment company, was to transport medical supplies and why Camila, a trained psychologist, acted to bring emotional support to children. Both assessed their Available Means to guide their goals and actions. Once volunteers settle on a goal, they gain Pre-commitments from the community, NGOs or government agencies. In Sofia's case, initial donations came from her network and she continually sought Pre-commitments from others for support. Precommitments lead to New Means or New Goals (Andersson, 2006) and both loop back and influence future Goals and Actions. Thus, opportunities are co-created with other agents (Sarasvathy, 2001, Dew et al., 2009). This feedback loop exemplifies the Experimentation Principle, where individuals are apt to abandon current actions and change course according to Available Means. In this way, Carlos started out donating batteries, transitioned to bottled water, then water filters and settled into working on community education and preparedness. Jesse started delivering food and water, transitioned to creating a satellite communication and payment system and was later developing an education and community center. Finally, through Flexibility, volunteers are open to Unexpected Contingencies. Their interventions were rarely preceded by a plan, opportunities were unknown until discovered (Ardichvili et al., 2003; Kirzner, 1997) and pursued as they presented themselves. Unexpected Contingencies and improvising are welcome, with Goals evolving and frequently leading to New Solutions or entirely New Ventures to solve problems. Informal initiatives emerge organically in response to directly experienced community needs (Lewis, 2015).

\section{Insert Figure 1 Here}

Second, the Affordable Loss Principle should frame the Goals and Actions of volunteers, however, in our study, volunteers unheeded the principle as they frequently placed the needs of the people and the community before theirs. One potential explanation is provided by Martina's (2018) twostage process model which posits that the level of investment is determined by willingness, which 
is in turn influenced by loss-aversion and affect. Volunteers evaluated the value of their involvement by asking whether it would still be worth attempting in the face of certain failure (Sarasvathy, 2014). Measures of success consisted of hard to quantify psychological variables that were influenced by their emotions. A positive affect, such as passion to do good, induces goal commitment and is related to riskier investments. This opens an interesting area for further exploration to understand why and when the Affordable Loss Principle is enacted or ignored.

Third, Effectuation Theory conveys new insights about volunteers' decisions and actions and how they contrast with those of established relief organizations. Causation processes involve clearly defined objectives that align with an organization's vision and searching for aid opportunities that meet those objectives. The organization envisions its undertaking and analyzes and plans its activities a priori, exploiting its current knowledge and resources to achieve this initial vision. The study found that application of effectuation vs causation processes depended on the informal volunteer categorization (Whittaker et al., 2015). Emerging Informal Volunteers applied Effectuation Principles of Experimentation, Flexibility and Pre-Commitments while mostly ignoring the Affordable Loss Principle. Extended Volunteer Organizations applied a mix of both Causation and Effectuation processes, disregarding the Experimentation Principle but relying on the Flexibility Principle. They had a predetermined plan and didn't let their available means and resources dictate the solutions they sought, instead choosing those that would let them accomplish their predetermined mission. Due to the uncertainty and a lack of experience, they remained flexible and attempted new approaches as long as they aligned with the original plans. Traditional relief organizations on the other hand relied on Causation processes, establishing a single "best" plan from the outset (Deligianni et al., 2017), and letting it guide their actions and decisions. They utilized their means to execute their plan and didn't stray far from the outlined path.

Finally, resilience has moved from the core idea of 'resisting and recovering' into 'adapting'; and from 'stability' to 'change'. This evolution of the concept is about adaptability and opportunities for innovation and not remaining locked into specific strategies. For these opportunities to become real, learning is a key aspect, in the sense that disasters could give the opportunity for reviewing the capacity of people and organizations, based on what worked and what didn't (Aldunce et al., 2015). Volunteer interviews supported this view when they described established relief organizations as slow, inflexible and in some instances ineffectual, delivering solutions that were out of sync with reality. Jesse's thoughts encapsulate this view: "Problem with NGOs: They have 
a preset expertise or mission. They stay in their lane, its limited what they can work on cause it's what they're set up to do and it's not always applicable." For some, solving these weaknesses was the reason they decided to become informal volunteers. Loreto acted in part to "Avoid bureaucracy and slowness." An effectual logic provides capacity for rapid deployment and pursuit of alternatives courses of action. Application of the Experimentation and Flexibility Principles allow the development of solutions that are better aligned with the needs of the community, improving the chances of success (Sanchez and Heene, 1997). Therefore, research should not associate Emerging and Extended Volunteers with a Causation approach exclusively. Future studies could employ developed instruments (Chandler et al., 2011; Brettel et al., 2012) to validate these findings, ascertain who applies effectual vs causal logic during disaster relief efforts and determine whether there are any added benefits to resilience building in doing so.

\section{Practical Implications}

Informal volunteers who work outside of the system have been traditionally viewed as a nuisance or a problem and their efforts are often undervalued or considered an intrusion (Whittaker et al., 2015; Helsloot and Ruitenberg, 2004; Scanlon et al., 2014; Stallings et al., 1985), especially considering their disregard of the Affordable Loss Principle, which places their financial resources, or their lives, at risk. Few studies have considered issues of safety and liability (Sauer et al., 2014), especially if volunteers lack the necessary knowledge, skills, equipment and training (Whittaker et al., 2015). Government and disaster relief organizations are thus tasked with managing and assuring their safety and well-being (Sauer et al., 2014). Bureaucracy and slow response times were some of the chief reasons why volunteers circumvented established procedures, regulations and laws (Stallings et al., 1985). They consequently took it up upon themselves to visit impacted areas and finance their ventures, thus placing themselves in physical and financial risk. As depicted in Figure 1, Available Means directly impact a volunteer's Goals and Actions. Providing access to affected areas, tools, information (Scanlon et al., 2014), and resources that fast-track financial aid applications, reduce paperwork and speed up response times can therefore indirectly reduce financial or personal risks. In doing so, it is important that organizations support informal volunteer efforts without attempting to appropriate or co-opt the efforts and do so in non-intrusive ways (Lewis, 2015). Self-help groups can be effectively nurtured as long as they are 'left to determine their own directions and priorities' (Burns and Taylor, 1998; Wilson, 1995; Wann, 1995). Some examples are: providing access to free and safe meeting spaces, signposting them to other services that they may require and using local 'formal' volunteers as facilitators, allowing informal volunteer efforts to keep their informal nature. Finally, 
volunteers are greatly influenced and continually searching for Pre-Commitments that lead to New Goals and New Means. Tools that aid their search for and acquisition of Pre-Commitments could be a valuable tool that can steer their efforts in the right direction and also help make their solutions sustainable.

Past research has demonstrated that citizen participation is a key component of disaster risk reduction and resilience building therefore "it is likely that 'informal' volunteers will provide much of the additional surge capacity required to respond to more frequent emergencies and disasters in the future." (Whitaker et al., 2015). There is broad consensus that stakeholder participation as opposed to expert-driven "command and control" approaches is decisive in post-disaster recovery (Wiek et al., 2010). Our results validate these studies and provide additional insights as to how informal volunteers' actions increase resilience and ameliorate recovery management problems. Through their experimentation and flexibility informal volunteers accelerate disaster recovery, recognizing opportunities (Monllor and Altay, 2016), working around bureaucracy and other roadblocks that would hinder the efforts of established organizations. Volunteers in our study also aided formal organizations, which often struggle with subsequent problems caused by deficits in recovery management (Wiek et al., 2010). Informal volunteers provide a long-term orientation to recovery management, as they remained in the affected community well past the initial phases of disaster recovery or turned their relief efforts into sustainable ventures through innovative business models. They adapted from meeting immediate needs of order restoration and stabilization to rebuilding and preparedness. Informal volunteers demonstrate entrepreneurial behavior that helps jumpstart the local economy, making for stronger and more resilient communities. These findings expand current theories regarding the facilitation of post-disaster business rehabilitation environment, which are lacking, and practical experiences in post-crisis economic recovery have yet to produce well-established conceptual knowledge (Régnier et al., 2008). Future studies could study whether existing programs set up to encourage and support entrepreneurship can also succeed with informal volunteers.

\section{Conclusion}

The goal of this paper was to increase our understanding of the informal volunteer phenomenon and the decisions and actions that guide these volunteers through their relief efforts to speed up recovery and increase community resilience. To accomplish this, we borrowed Effectuation Theory from the entrepreneurship field in order to bring a much needed theoretical lens to the topic. Welter et al. (2016) encouraged fields outside entrepreneurship to explore the value of 
effectuation in their contexts and we believe our study greatly helps informal volunteerism research move forward and past current efforts to simply define and categorize the concept. In many ways informal volunteers act just like entrepreneurs, recognizing an opportunity where others see chaos or problems and taking initiative to exploit them and create value. This opens up the possibility of a whole set of theories that can be applied to understand and promote informal volunteer behavior and have a positive impact on future disaster recovery and preparation efforts. Indeed, the measurable and ameliorative role that entrepreneurship can play in the case of disasters, along with the value it can add to such settings, is under-researched (Bullough et al., 2014). Disasters are destructive events that generate social distress and economic tension and the benefits of attempts to understand volunteer decision making that can increase resilience and prepare communities for future events is unquestionable. 


\section{References}

Aldunce, P., Beilin, R., Howden, M., \& Handmer, J. (2015). Resilience for disaster risk management in a changing climate: Practitioners' frames and practices. Global Environmental Change, 30, 1-11.

Ardichvili, A., Cardozo, R., and Ray, S. (2003). "A theory of entrepreneurial opportunity identification and development." Journal of Business Venturing, Vol. 18 No.1, pp. 105-123. doi:10.1016/s0883-9026(01)00068-4

Arend, R., Saroogi, H., and Burkemper, A. (2015). "Effectuation as ineffectual? Applying the 3E theory- assessment framework to a proposed new theory of entrepreneurship". Academy of Management Review, Vol. 40, pp. 630-651.

Brettel, M., Mauer, R., Engelen, A., and Küpper, D. (2012). "Corporate effectuation: Entrepreneurial action and its impact on R\&D project performance". Journal of Business Venturing, Vol.27 No. 2, pp. 167-184.

Brinkmann, J., Grichnik, D., and Kapsa, D. (2010). "Should entrepreneurs plan or just storm the castle? A meta-analysis on contextual factors impacting the business planningperformance relationship in small firms." Journal of Business Venturing, Vol. 25 No.1, pp. 24-40.

Burns, D. and Taylor, M. (1998) Mutual Aid and Self-help: Coping Strategies for Excluded Communities, Bristol: Policy Press

Chandler, G.N., De Tienne, D.R., and Mumford, T.V. (2007). "Causation and effectuation: Measurement development and validation". Frontiers of Entrepreneurship Research, Vol. 27 No.13, pp. 3.

Chandler, G. N., De Tienne, D. R., McKelvie, A., and Mumford, T. V. (2011). "Causation and effectuation processes: A validation study". Journal of business venturing, Vol. 26 No. 3 , pp. 375-390.

Concha-Saldias, C., Micheletti, S., Rasse-Figueroa, A., and Olivares-Larraín, R. (2015). "Postearthquake reconstruction in the Maule's rurality". Bitácora Urbano Territorial, Vol. 25 No.1, pp. 89-98.

Corbin, J., Strauss, A.L. and Strauss, A., (2015). Basics of qualitative research. Sage.

Deligianni, I., Voudouris, I., and Lioukas, S. (2017). "Do effectuation processes shape the relationship between product diversification and performance in new ventures?". Entrepreneurship Theory and Practice, Vol. 41 No. 3, pp. 349-377. 
Dew, N., Read, S., Sarasvathy, S.D., and Wiltbank, R. (2009). "Effectual versus predictive logics in entre- preneurial decision-making: Differences between experts and novices". Journal of Business Venturing, Vol. 24 No. 4, pp. 287-309.

Dimov, D. (2010). "Nascent entrepreneurs and venture emergence: Opportunity confidence, human capital, and early planning". Journal of Management Studies, Vol. 47 No. 6, pp. 1123-1153.

Farazmand, A. (2017). Crisis and Emergency management. Crisis and Emergency Management: Theory and Practice., 1.

Field, C. B., Barros, V., Stocker, T. F., and Dahe, Q. (2012), Managing the risks of extreme events and disasters to advance climate change adaptation: special report of the intergovernmental panel on climate change. Cambridge University Press.

Fisher, G. (2012). Effectuation, causation, and bricolage: A behavioral comparison of emerging theories in entrepreneurship research. Entrepreneurship theory and practice, 36(5), 1019-1051.

Gibbert, M., Ruigrok, W., \& Wicki, B. (2008). What passes as a rigorous case study? Strategic Management Journal, 29(13), 1465-1474. https://doi.org/10.1002/smj.722

Glaser, B. G., \& Strauss, A. L. (2017). Discovery of grounded theory: Strategies for qualitative research. Routledge.

Gregoire, D. A., \& Cherchem, N. (2017). Looking for a way Forward: A Structured Literature Review of Effectuation Research. In Academy of Management Proceedings, (Vol. 2017, No. 1, p. 12907). Briarcliff Manor, NY 10510: Academy of Management.

Helsloot, I., and Ruitenberg, A. (2004). "Citizen response to disasters: a survey of literature and some practical implications". Journal of contingencies and crisis management, Vol. 12 No. 3, pp. 98-111.

Hincks, J. (2017). "The Disturbing Numbers on Puerto Rico a Month After Maria", available at: http://time.com/4988841/puerto-rico-hurricane-maria-numbers-recovery/ (accessed 24 April 2019).

Jiang, Y., \& Rüling, C. C. (2019). Opening the black box of effectuation processes: characteristics and dominant types. Entrepreneurship Theory and Practice, 43(1), 171-202.

Kirzner, I. M. (1997). "Entrepreneurial discovery and the competitive market process: An Austrian approach". Journal of economic Literature, Vol. 35 No. 1, pp. 60-85.

Lewis, S. (2015). "Learning from communities: The local dynamics of formal and informal volunteering in Korogocho, Kenya". IDS Bulletin, 46(5), 69-82.

Martina, R. A. (2018). Toward a theory of affordable loss. Small Business Economics, 1-24. 
McLennan, B., Whittaker, J., and Handmer, J. (2015). "Emergency volunteering in Australia: transforming not declining". Australia: Bushfire and Natural Hazards CRC.

McGrath, R. G. (1995). "Advantage from adversity: learning from disappointment in internal corporate ventures". Journal of Business Venturing, Vol. 10 No. 2, pp. 121-142.

Mechler, R. (2003). Macroeconomic impacts of natural disasters. The World Bank.

Monllor, J., and Altay, N. (2016). "Discovering opportunities in necessity: The inverse creative destruction effect". Journal of Small Business and Enterprise Development, Vol. 23 No. 1, pp. 274-291. doi:10.1108/jsbed-10-2014-0172

Monllor, J., and Murphy, P. J. (2017). "Natural disasters, entrepreneurship, and creation after destruction: a conceptual approach". International Journal of Entrepreneurial Behavior \& Research, Vol. 23 No. 4, pp. 618-637.

Morrish, S. C., \& Jones, R. (2019). Post-disaster business recovery: An entrepreneurial marketing perspective. Journal of Business Research

Muñoz, R. M. (2010). “Terremoto y tsunami del 27 de febrero de 2010. Efectos urbanos en localidades de la provincia de Arauco". Urbano, pp. 43-62.

Pachauri, R. K., Allen, M. R., Barros, V. R., Broome, J., Cramer, W., Christ, R., and Dubash, N. K. (2014). Climate change 2014: synthesis report. Contribution of Working Groups I, II and III to the fifth assessment report of the Intergovernmental Panel on Climate Change IPCC. pp. 151. IPCC.

Palmié, M., Huerzeler P, Grichnik D, Keupp MM, Gassmann O., (2018) "Some principles are more equal than others: Promotion- versus prevention-focused effectuation principles and their disparate relationships with entrepreneurial orientation". Strategic Entrepreneurship Journal. pp. 1-25.

Patton, Michael. 2015. Qualitative Research and Evaluation Methods: Integrating Theory and Practice, 4th ed. Thousand Oaks: SAGE Publications.

Régnier, P., Neri, B., Scuteri, S., \& Miniati, S. (2008). From emergency relief to livelihood recovery: lessons learned from post-tsunami experiences in Indonesia and India. Disaster Prevention and Management: An International Journal, 17(3), 410-430.

Robles, F., Davis, K., Fink, S., and Almukhtar, S. (2017, December 08). "Official Toll in Puerto Rico: 64. Actual Deaths May Be 1,052." Retrieved from https://www.nytimes.com/interactive/2017/12/08/us/puerto-rico-hurricane-maria-deathtoll.html?pagEthanted=all 
Sanchez, R., and Heene, A. (1997). "Reinventing strategic management: New theory and practice for competence-based competition. European". Management Journal, Vol. 15 No. 3, pp. 303-317.

Sarasvathy, S. D. (2001). "Causation and effectuation: Toward a theoretical shift from economic inevitability to entrepreneurial contingency". Academy of Management Review, Vol. 26 No. 2, pp. 243-288.

Sarasvathy, S. D. (2008). Effectuation: Elements of entrepreneurial expertise. Northampton, MA: Edward Elgar Publishing.

Sarasvathy, S. D., Kumar, K., York, J.G., and Bhagavatula, S. (2014). "An effectual approach to international entrepreneurship: Overlaps, challenges and provocative possibilities". Entrepreneurship Theory and Practice, Vol. 38 No. 1, pp. 71-93.

Sauer, L. M., Catlett, C., Tosatto, R., and Kirsch, T. D. (2014). "The utility of and risks associated with the use of spontaneous volunteers in disaster response: a survey". Disaster Medicine and Public Health Preparedness, Vol. 8 No. 1, pp. 65-69.

Scanlon, J., Helsloot, I., and Groenendaal, J. (2014). Putting it all together: Integrating ordinary people into emergency response.

Stallings, R. A., and Quarantelli, E. L. (1985). "Emergent citizen groups and emergency management." Public administration review, Vol. 45, pp. 93-100.

Strandh, V. (2019). Crisis Volunteerism is the New Black? Exploring the Diversity of Voluntary Engagement in Crisis Management. Risk, Hazards \& Crisis in Public Policy.

Strandh, V., and Niklas E. (2018). "Emergent groups in disaster research: Varieties of scientific observation over time and across studies of nine natural disasters." Journal of Contingencies and Crisis Management 26, no. 3: 329-337.

Vera, D., and Crossan, M. (2005). "Improvisation and innovative performance in teams". Organization Science, Vol.16 No.3, pp. 203-224.

Wann, M. (1995) Building Social Capital: Self-help in the Twenty-first Century Welfare State, London: Institute for Public Policy Research.

Welter, C., Mauer, R., and Wuebker, R. J. (2016). "Bridging behavioral models and theoretical concepts: effectuation and bricolage in the opportunity creation framework". Strategic Entrepreneurship Journal, Vol,10 No. 1, pp. 5-20.

Weichselgartner, J. (2001). Disaster mitigation: the concept of vulnerability revisited. Disaster Prevention and Management: An International Journal. 
Whittaker, J., McLennan, B., and Handmer, J. (2015). "A review of informal volunteerism in emergencies and disasters: Definition, opportunities and challenges". International Journal of Disaster Risk Reduction, Vol. 13, pp. 358-368.

Wiek, A., Ries, R., Thabrew, L., Brundiers, K., \& Wickramasinghe, A. (2010). Challenges of sustainable recovery processes in tsunami affected communities. Disaster Prevention and Management: An International Journal, 19(4), 423-437.

Wilson, J. (1995) Two Worlds: Self-help Groups and Professionals, Birmingham: British Association of Social Workers

Wiltbank, R.E. and Sarasvathy, S.D. (2010). "What effectuation is not: Further development of an alternative to rational choice". Academy of Management Conference, Montreal Canada.

Yin, R. K. (2013). Case study research: Design and methods (5th Edition). Los Angeles: SAGE Publications, Inc. 
Table 1 - Contrasting Causation and Effectuation Processes

\begin{tabular}{|c|c|c|}
\hline Issue & Causal Position & Effectual Position \\
\hline $\begin{array}{l}\text { View of the } \\
\text { Future }\end{array}$ & $\begin{array}{l}\text { Prediction. Views the future as a } \\
\text { continuation of the past that can be } \\
\text { predicted. }\end{array}$ & $\begin{array}{l}\text { Creation. Views the future as contingent } \\
\text { on actions by willful agents and a residual } \\
\text { of actions taken. Prediction is } \\
\text { unimportant. }\end{array}$ \\
\hline $\begin{array}{l}\text { Basis for } \\
\text { Commitment }\end{array}$ & $\begin{array}{l}\text { Should. Commit as a course of } \\
\text { maximizing, analysis, and what } \\
\text { should be done. }\end{array}$ & $\begin{array}{l}\text { Can. Do what you can rather than what } \\
\text { your prediction says you should. }\end{array}$ \\
\hline $\begin{array}{l}\text { Basis for } \\
\text { Taking Action } \\
\text { and Acquiring } \\
\text { Stakeholders }\end{array}$ & $\begin{array}{l}\text { Goals. Let goals determine sub- } \\
\text { goals. Commitment to particular } \\
\text { sub-goals determined by larger } \\
\text { goal constrained by means. }\end{array}$ & $\begin{array}{l}\text { Means. Actions emerge from means and } \\
\text { imagination. Stakeholder commitments } \\
\text { and actions lead to specific sub-goals. } \\
\text { Feedback from achievement/non- } \\
\text { achievement of sub goals leads to design } \\
\text { of major goals. }\end{array}$ \\
\hline Planning & $\begin{array}{l}\text { Commitment. Path selection is } \\
\text { limited to those that support a } \\
\text { commitment to an existing goal. }\end{array}$ & $\begin{array}{l}\text { Contingency. Paths are chosen that } \\
\text { allow more possible options later in the } \\
\text { process, enabling strategy shift as } \\
\text { necessary. }\end{array}$ \\
\hline $\begin{array}{l}\text { Predisposition } \\
\text { Toward Risk }\end{array}$ & $\begin{array}{l}\text { Expected Return. Pursue the (risk } \\
\text { adjusted) maximum opportunity, } \\
\text { but not focus on downside risk. }\end{array}$ & $\begin{array}{l}\text { Affordable Loss. Don't risk more than } \\
\text { can afford to be lost. Calculation is } \\
\text { focused on the downside potential. }\end{array}$ \\
\hline $\begin{array}{l}\text { Attitude } \\
\text { Toward } \\
\text { Outside Firms }\end{array}$ & $\begin{array}{l}\text { Competition. Concerned with } \\
\text { competition and constrain task } \\
\text { relationships with customers and } \\
\text { suppliers to just what is necessary. }\end{array}$ & $\begin{array}{l}\text { Partnership. Create a market jointly, } \\
\text { building your market together with } \\
\text { customers, suppliers and even } \\
\text { prospective competitors. }\end{array}$ \\
\hline
\end{tabular}


Table 2. Disaster Cases, Informal Volunteers and their Ventures

\begin{tabular}{|c|c|c|c|c|}
\hline \multirow{2}{*}{ Case } & \multirow[b]{2}{*}{ Volunteer } & \multirow[b]{2}{*}{ Type } & \multicolumn{2}{|c|}{ Unit of Analysis } \\
\hline & & & Venture & Location \\
\hline Hurricane & Jesse & Emergent & Satellite Payment \& & Various, Puerto Rico \\
\hline \multirow[t]{3}{*}{ Maria } & & & Communications & \\
\hline & Ethan & Emergent & $\begin{array}{l}\text { Medical equipment and } \\
\text { medicine donations }\end{array}$ & Mayagüez, Puerto Rico \\
\hline & Carlos & Emergent & $\begin{array}{l}\text { Donations and } \\
\text { educational program }\end{array}$ & San Juan, Puerto Rico \\
\hline \multirow[t]{3}{*}{ Valparaiso Fire } & Sofia & Emergent & Donations and & Valparaiso, Chile \\
\hline & & & Community Center & \\
\hline & Patricio & Extended & $\begin{array}{l}\text { Shelter and Volunteer } \\
\text { Center }\end{array}$ & Valparaiso, Chile \\
\hline \multirow[t]{3}{*}{$\begin{array}{l}\text { Chile } \\
\text { Earthquake }\end{array}$} & Camila & $\begin{array}{l}\text { Emergent \& } \\
\text { Extended }\end{array}$ & Psychological Aid & $\begin{array}{l}\text { San Antonio \& Tapihue } \\
\text { Chile }\end{array}$ \\
\hline & Loreto & Extended & Psychological Aid & Batuco, Chile \\
\hline & Ignacio & Established & Construction & Linares, Chile \\
\hline
\end{tabular}


Figure 1: Informal Volunteer Effectuation Framework

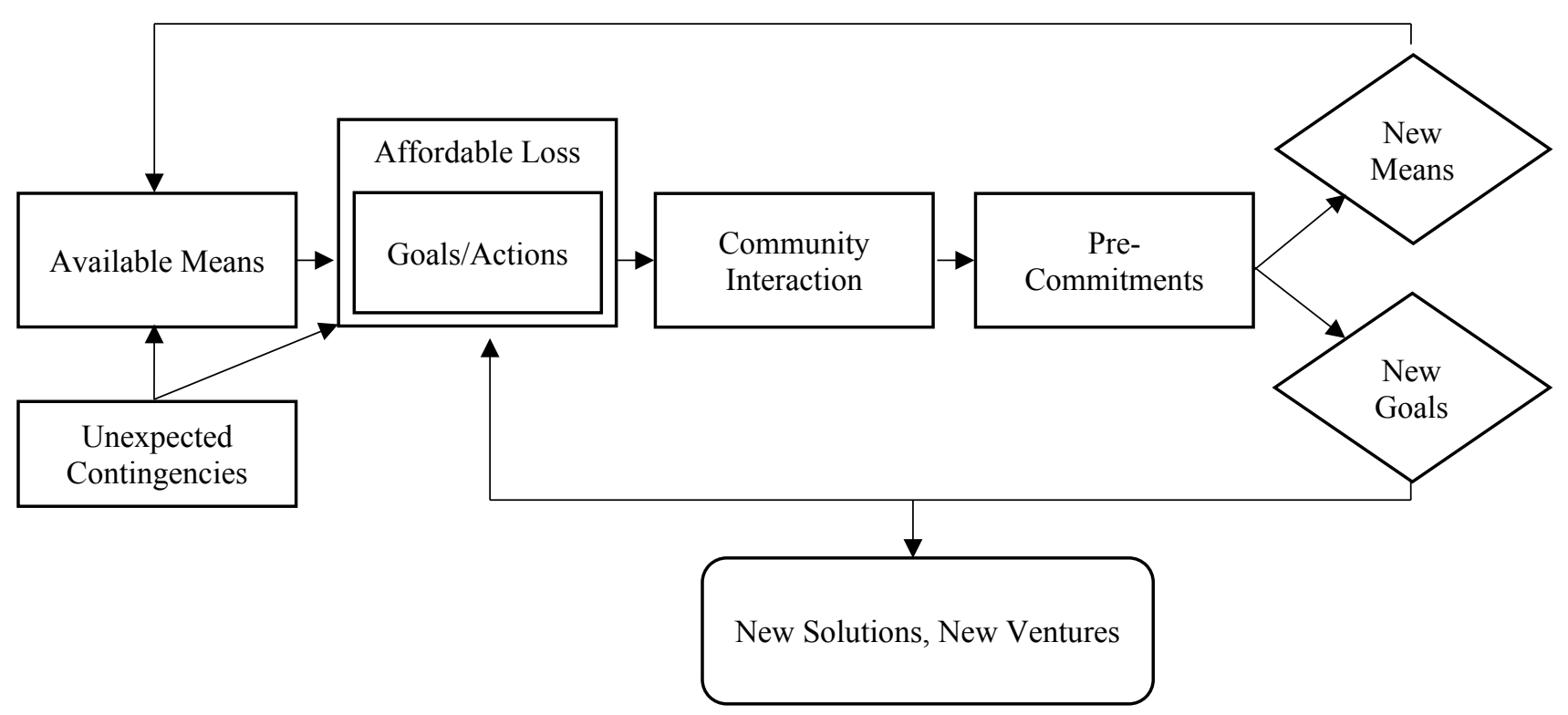

